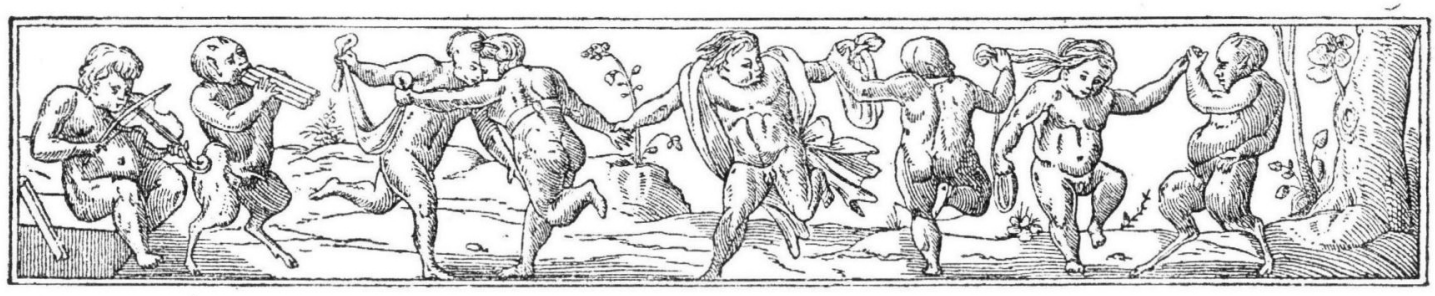

\title{
BRIEVEN VAN BON. VULCANIUS EN HENR. SMETIUS,
}

\author{
UITGEGEVEN DOOR
}

- Dk. P. C. MOlhuYSEN.

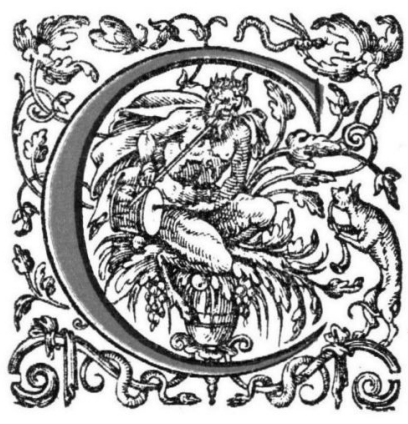

URATOREN der jonge Leidsche hoogeschool hadden in 1591 aan Franciscus Junius, den beroemden Heidelberger theoloog, ten tweeden male een plaats als professor te Leiden aangeboden. De brief van hun secretaris JAN vas Hout, d.d. I9 Aug. I59 I is gedrukt in het tweede gedeelte van Colomesius' uitgave van G. J. Vossius' briefwisseling (I691) p. 330. Ook de Senaat, wiens advies in dezen ongetwijfeld gevolgd was, had reeds den

25 Juli door zijn secretaris, BON. VULCANIUS, JuniUs met deze keuze in kennis gesteld; of deze brief nog bestaat weet ik niet.

Geen dezer twee brieven vond Junius meer in Heidelberg. Hij was kort te voren in dienst van HENDRIK IV getreden en als veldprediker de Duitsche huurtroepen gevolgd, die TURFNNE naar Frankrijk voerde. Eerst in December van dat jaar keerde hij naar HEIDELBERG terug om orde op zijn zaken te stellen, en dan met zijn gezin voor goed naar Frankrijk te verhuizen. Daar kreeg hij toen Vulcanius' brief in handen. Den anderen zal de tabellio academicus, de ,bode met de bus", die door Curatoren naar Heidelberg gezonden was, mede terug genomen hebben, toen hij Junius daar niet meer aantrof; 
zoo toch wordt het verklaarbaar, waarom VAN HOUT in zijn "Dachbouck" 1 ) een afschrift van JUNIUS' antwoord aan VULCANIUS maakte, terwijl van een antwoord op den brief van Curatoren niets blijkt.

Ofschoon deze brief van JuNius aan Vulcanius buiten mijn bestek valt, acht ik het niet ondienstig hem hier in zijn geheel te laten volgen, daar hij aan de aandacht van Junius' biograaf CuNo ${ }^{2}$ ) ontgaan is.

\title{
Fr. Junius B. Vulcanio S.P.
}

\begin{abstract}
Neque alteras a te litteras mi Vu.CANI ante has vidi, neque has ipsas quas videre contigit ante quatriduum vidi quum ex Gallia a rege profectus essem, et reversus ad meos. Hanc moram neque tu pro tua humanitate neque viri nobilissimi, domini amplissimi, Curatores vestrae Academiae, neque collesa reliqui pro sua prudentia iniquo animo ferre possunt; nam in me culpa nulla. Honorificum vestrum de me iudicium video magis ex vestra humanitate factum quam merito meo: postulato si non respondeam, iniquus sim, si non satisfaciam ingratus. Sed est quod in bac causa familiariter vobis exponam nec potest a vobisignorari. De hoc consilio vestro antea quidem audiveram et mirabar tam lente agi quum fuissem istuc quamvis renitentibus multorum vocibus abiturus. Sed antevertit regis christianissimi postulatım cxspectationem meam et praeter exspectationem mcam, nam senectute otium in repub. parare maluissem quam in arduis rebus quac minantur mihi occupari. Sed quid. Ad regem veni liber, discessi scrvus, mandavit ut ante aestatem revertar operam in Gallia consumturus. Omnino constitui proximo senatu huic academiae renuntiare utut in Gallia res abeant (bene abituras confido in domino) et aestate proxima aut transire ad vos aut per vos (ut mandatum est mihi) transire in Galliam; nam hac lege teneor, qua si me Deus absolverit, vester sim. Aedium tuarum usum a te offerri humaniter, ingentes gratias habeo. Lipsius de quo scribis, Leodii est; fueram cum illo acturus coram ante dies XV, sed dissuaserunt boni non tam hominis metu quam domus in qua versatur. Non abstinebo tamen quin appellem saltem semel. De MeLisso quod scribis curabo. Bene vale vir clarissime et bonos omnes (si non est molestum) nostrique amantes saluta. Heidelberga die Sabbati 4 Decembris 1591 .
\end{abstract}

JUNIUS had bij zijn vertrek naar Frankrijk aan zijn zwager DE SMET de zorg voor zijn familie en zijn zaken opgedragen. Deze opende den brief van VUlCANIUS; hij herkende in den schrijver een makker uit zijn jeugd met wien hij school had gegaan, en zoo ontwikkelde zich een correspondentie tusschen beiden, waarin zij wederzijds de herinneringen aan hun jeugd deden herleven, en elkaar over hun familie en afkomst inlichtten. In een korten tijd worden over en weer een paar brieven gewisseld, waarna de correspondentie plotseling weder ophoudt, trots VulCANIUS' aansporing in zijn eersten brief om de vriend-

1) Het "Darhbouck" van JAN van Hour loopt van Nov. 1580 tot Juni '94. Hij teekende daarin aan al wat er aangande de Universiteit te vermelden viel, met aschriften van in- en uitgaande brieven. Het is hoogst belangrijk voor de geschiedenis der Universiteit, en in 't algemeen weinig geraadpleegd, daar vaN HoCT bizonder onduidelijk schrijft. Het verdiende in zijn geheel uitgegeven te worden.

2) $\mathrm{H}$. W. Cuno, Francisius Funius der Aeltere... sein Lebin und Wirken, scine Schriften und Briefe. $189 \mathrm{I}$. 
schap in stand te houden. Trouwens, te verwonderen behoeft ons dit niet, als we bedenken dat beide mannen niet veel meer dan den naam met elkaar gemeen hadden; en de brieven ontleenen hun belang dan ook hoofdzakelijk daaraan, dat zij authentieke levensbijzonderheden geven over twee mannen, die een belangrijke plaats bekleed hebben in de geleerde geschiedenis van hun tijd.

Een kleine 20 jaar houdt de briefwisseling dan op. In een brief van pr. kal. Maias 1609 schrijft JANus Gruterus, de schoonzoon van SMETIUS aan VulCANius o. a.: "... ego certe virtutem tuam... ore etiam frequenter praedico, apud amicos potissimum, imprimis vero socerum meum condiscipulum tuum Henricum Smetrum qui te officiose salutat". Vulcanius, die de 70 al gepasseerd was en wiens geheugen niet zoo helder meer was, kon zich niet meer herinneren wie die SMETIUS toch was, en hij zal er bij GRUTER naar gevraagd hebben; want deze schrijft hem, d.d. 20 Sept. 1610') „...Grata erit SMETIO quaestio tua, de qua scribam tibi simulatque domum venero".

Maar SMerius wilde zelf die vraag wel beantwoorden, en den ien Dec. van hetzelfde jaar zond hij Vulcanius nogmaals een kort levensbericht, dat door dezen in Maart d.a.v. beantwoord werd; Smetius schrijft I4 Sept. I6 I nog eens, en dan is de correspondentie voor goed uit.

De brieven van Smetius zijn alle eigendom der Leidsche Bibliotheek, die van 22 April $1592\left(N^{\circ}\right.$. 5) kochten wij kort geleden bij den antiquaar STARGARDTH; hij komt ook voor in de auctie J. v. VOLLENHOVEN, bij BRILL, te Leiden in 1894 gehouden. De andere vier zijn met de overige handschriften en brieven van Vulcanius in 1614 voor de bibliotheek angekocht.

De oudste 2 brieven van Vulcanius (No. 2 en 4 ) bevinden zich in het handschrift Germ. 804 der Universiteits-Bibliotheek te Heidelberg; door de zeer gewaardeerde welwillendheid van de directie werd het voor mij te Leiden gedeponeerd. Vulcanius' laatste brief ( $\left.\mathrm{N}^{\circ} .7\right)$ wordt in de Vaticana te Rome beward, in het vroegere Heidelbergsche hs. Palatinus Latinus No. Igo3. Beide deze codices bevatten brieven aan SMETIUs gezonden. Het vermoeden ligt niet ver dat SMETIUS' schoonzoon, de bibliothecaris GruTER, de brieven in deelen heeft laten binden en in de bibliotheek plaatsen. Ik schreef dezen brief zelf te Rome af, toen ik daar in het voorjaar 1906 vertoefde om bouwstoffen voor de vaderlandsche geleerdengeschiedenis te verzamelen. Dr. J. A. F. OrbaAN, door de Nederlandsche Regeering belast met kunsthistorische nasporingen aan het Ned. Historisch Instituut aldaar, vestigde mijn aandacht op dezen brief, waarvoor hem hier nogmaals dank wordt gezegd. Een enkel woord thans nog over de schrijuers der brieven zelf.

1) Beide brieven in originali op de Leidsche bibliotheek. 
Hendrik SMetius was 29 Juni 1537 te Aalst geboren uit een aanzienlijk geslacht, waarop hij trotsch was, en waarover hij herhaaldelijk spreekt, zoo in deze brieven als in het lange gedicht voor zijn "Miscellanea medica" en vooral in de "Parentalia". Aan het jaartal I 537 kan geen twijfel zijn, maar CuNo, Franciscus Funius, p. 220 deelt zijn grafschrift mede, waarop 1536 als geboortejaar staat. Of dit een vergissing is van hem, of van ANDREAE, Monumenta Heidelhergensia, dien hij citeert, weet ik niet; maar MELCHIOR ADAM in zijn Vitae Germanorum medicorum p. 4 I 5 geeft ditzelfde grafschrift met het jaartal 1537.

$\mathrm{Hij}$ is te Heidelberg, I5 Maart 1614 overleden. ADAM, wiens boek in I620 te Heidelberg uitkwam, en die SMeTIUS in Heidelberg kan gekend hebben, het bovengenoemde grafschrift, en alle andere biographische werken noemen dit jaar; alleen de Biographie Nationale laat hem 1612 sterven; waarschijnlijk is ook dit een drukfout.

Hij was eerst gehuwd met JoHanna VAN DE CoRnPUT (CORPUT) een dochter van den burgemeester van Breda. Hij was dus een zwager van HENDRIK VAN DE CORNPUT, den Dordtschen predikant, en van JAN, den beroemden genieofficier, die Steenwijk tegen ReNnenberg verdedigde. Hem is de "Prosodia" opgedragen. Franciscus Junius was met een zuster, Elisabethi van ide CORNPUT gehuwd.

Een dochter van Smetius, naar haar moeder Johanna genaamd, huwde in 1592 met den reeds genoemden JANUS GRUTERUS.

Te Gent ging hij school bij den bekenden paedagoog JaN OTHO ') en het was daar dat hij VulCaNius leerde kennen; op zijn $15^{\mathrm{e}}$ jaar, in den zomer $\mathrm{I} 55_{2}$ ging hij naar de Universiteit te Leuven, tot I 554; VULCANIUS is eerst in $\mathbf{1 5 5 5}$ te Leuven gekomen. De vriendschap is daar dus niet voortgezet.

Van SMETIUS' werken is verreweg het bekendste zijn Prosodia, bij zijn leven en ook later herhaaldelijk gedrukt, o. a. nog in $1683^{2}$ ), een schoolboek om de jeugd de kwantiteit der lettergrepen te leeren. Hoezeer het in trek was toont het feit dat de $7^{\mathrm{e}}$ uitgave de kolossale oplage van 2000 exemplaren had. De Miscellanea medica, waarin hij Galenus' leer verdedigt en tegen Paracelsus te velde trekt, zagen I6I i het licht bij Jonas RHodius te Frankfort.

De fuvenilia, de gedichten waarover SMETIUs herhaaldelijk in deze brieven spreekt, verschenen I594. Het boekje bestaat uit 3 stukjes, elk met afzonderlijke pagineering. De titel is: HeNRICI SMETsII | Alostani|Fuvenilia | sacra: | Regum Fudaicorum | lib. tres. | Susannae lib. unus |ad|illustrem Heroa, | Simo-

1) Zie over hem en zijn ondermeester OLIVARIUS = OlieschlaGER, de Biographie Nationale.

2) Ik ken uitgaven: Frankfort I609, I630, Londen I628, Amsterdam I648, I674, I68 3 . 
nem | Lippiae Comitem. |(Vignet) Heidelbergae, | Typis Smesmannianis | An. CIDIOXCIIII.

Het 2 e en 3 e stukje hebben tot titel "Fuvenilia miscella" en "Parentalia".

Het eerste gedeelte bevat de Reges en Susanna, het tweede het epos de Medicinae antiquitate, later in de Miscellanea herdrukt, Elegiarum libb. II, Odarum liber unus, Phocylidae poëma, Pythagorae carmen, Batrachomyomachia, en ten slotte een Carminum libellus adoptivus, gedichten van anderen op den auteur; het derde gedeelte, de Parentalia, is een reeks gezangen op de verschillende leden van 't gesiacht DE SMET, met de aangehuwde familie.

Het boekje is vrij zeldzaam. Het exemplaar der Koninklijke Bibliotheek in den Haag was een present-exemplaar met de eigenhandige inscriptie: JOHANNI BRANTIO ") viro doctiss. gymnasiarchae Vesaliensi mittit auctor.

Van de "oratio de febri tertiana intermattente", volgens de Biogr. nationale in 587 te Heidelberg uitgekomen, heb ik geen exemplaar kunnen vinden.

Er bestaat een portret van SMETIUS, aetat. 62, met het jaartal I 598 en met epigram van JANUS GruTERUS. Het komt met zijn wapen in verschillende uitgaven voor, in de Miscellanea, in de Prosodia van 1609 , en naar dezelfde plaat, maar opgesneden, zonder jaartal en zonder GRUTER's naam in die van $\sigma_{3} O$.

$E_{r}$ is in de brieven een paar maal sprake van Encomia Dousana. JAN VAN DER DOES had in 1584 een bundeltje gedichten, "Epodon ex puris iambis libri II" uitgegeven en opgedragen aan JoHANNEs PosTHIUs, geneesheer toen te Würzburg, later in Heidelberg. Postulus van zijn kant wist van verschillende vereerders van Dousa lofdichten op hem te krijgen en gaf deze in 1587 uit onder den titel: "Encomia Dousana. Hoc est varia variorum Poütarum in honorem Jani Dousae NoRdovicis, viri nobulissimi carmina. Edita a JOANne POSThio Germershemio, Principum Palat. ad Rhenum Archiatro. Men vindt er gedichten van Melissus, Sylburg, Modius, en andere humanisten van naam. Ook Smetius gaf een bijdrage ${ }^{2}$ ), gedagt. 20 Oct. I585, waarin hij de jeugdige Academie gedenkt en haar professoren. Op VULCANIUS slaat het volgende:

\section{Eu orthodoxus Eutiches Falier aigens \\ Locutionis Atticae peritia: \\ Faber faceti et elegantis ingenî \\ Mihique cartes inde ab ipsa ephebia.}

Over Vulcanius' sterfjaar is nog al eens verschil van meening geweest. Sweertics in zijn Athenae Belgicae zegt dat hij overleed M. DC. X. IX Oct.:

1) Zie Zschr. Bergisch. Gesch. ler. IV p. II5 en volg.

2) Ook in zijn Fuvenilia opgenomen, ze ged. p. 129 .

Oud-Holland, 1908 . 
dus 9 Oct. 16ro; het staat thans, vooral na RAMmelman ElsevieR's artikel in de Berigten van het Hist. Gezelschap te Utrecht 2e Stuk (1848) p. $80 \mathrm{vv}$. voldoende vast, dat hij 9 Oet. I6I4 stierf, en men zal dus moeten aannemen dat bij SweErtius voor de IX een IV is uitgevallen. Dat men het foutieve jaar toch als het juiste heeft willen beschouwen vindt zijn reden hierin, dat zijn boekerij den I 5 en November I6ro zoude zijn verkocht (REIFFENBERG in Bibliophile Belge IV, p. 3I2). In werkelijkheid zijn toen hoofdzakelijk zijn gedrukte werken verkocht, zijn handschriften behield hij en deze gingen eerst na zijn dood aan de Universiteit over '). De reden waarom hij reeds in 16 ro zijn boeken verkocht, was zijn voortdurende ziekte; VULCANIUS die veel en hard gewerkt had, moest reeds in 1607 zijn pensioen nemen. Zijn brief van i 8 Maart 16I I ( $\mathrm{N}^{\circ} .7$ ) is in dit opzicht zeer leerrijk. „Reeds 4 jaar lang lijd $\mathrm{ik}$ onder allerlei kwalen; het zou vervelend voor $U$ zijn alles te moeten aanhooren; maar 't komt hierop neer dat gezicht, gehoor, handen, voeten en zijden hun dienst weigeren, en ik totaal hulpbehoevend ben. Ik ben nu reeds 14 maand mijn kamer, of althans mijn deur niet uit geweest, en men heeft dan ook al verteld dat ik dood was." Dat hij in zulke omstandigheden zijn boeken verkocht was eenigszins begrijpelijk; een wetenschappelijke zelfmoord, als REIFFENBERG het noemt, was het onder deze onstandigheden dan ook allerminst.

Zijn familienaam DE SMET vertaalt VULCANIUS op verschillende wijzen. Fortunatus Faber noemt hij zich b.v. in zijn Thesaurus; als ex libris vindt

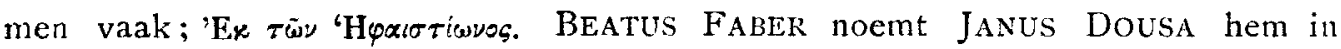
zijn Epodon libri; Eutyches FAbER, Smetius in de Encomia. Er zijn wellicht nog mecr varianten. Doch dat de vertaling "VulCanius" oorspronkelijk van ERASMUS afkomstign is, was geloof ik niet bekend.

Of Petrus Vulcanius in No. 7 genoemd onk een „DE SMET” was, blijkt niet; mogelijk dankte hij zijn naam alleen aan zijn gebrek. Hij was toch evenals VULCANus, mank.

I.

S. P. Literas tuas, quas ad Franc. JUNIUM a(ff)inem ') meum carissimum, die Jacobi ${ }^{3}$ ) scriptas emisisti, tabellarius XXIII Septemb. (dem)um reddidit, nona nimirum hebdomade a scriptione. Quas ex iussu affinis mei, quum discederet, aperui. Discessit autem hinc in Galliam $X$ Augusti una cum vicecomite TURENNIo, copias germanicas ducente, vocatus quidem a rege, attamen non destitutus Illustriss. nostri Principis consensu neque Academiae nostrae permissu, ad tempus; relicta interim hic familia ct omni supellectile. Speramus autem reditum sub brumam.

1) Zie mijn Geschiedenis der Univ. Bibl. te Leiden, p. 22.

2) Door gaten in den brief is hier en daar een gedeelte van een woord uitgevallen; wat ik aanvulde staat tusschen ( ).

3) $25 \mathrm{Juli}$. 
Literas tuas priores accepisse eum multo ante discessum hinc coniicio, quod se Lugdunum invitatum sicut et Witebergam et Franiqueram et alio ex ipso audisse meminerim. Responderit necne, ignoro. P. Mecisso salutem a te officiosam hodie annunciavi et quid petas indicavi. Idem plurimum te vicissim salvere iubet, additque codicum Graecorum manuscriptorum, qui in bibliotheca Palatina exstant, titulos et catalogum usque ad numerum, ni fallor, 330 , consignatos adiumento SYLBURGI et calamo, nundinis pascalibus in lucem prodituros et quidem codice ron mediocri $\left.{ }^{1}\right)$. Cuius beneficio voti tui compos reddi po(ter)is. Forte circa idem tempus poëmata (quae)dam mea, iuvenili aetate scripta, inter (quae) Regum iudaicorum libri 3, Epos de arte (me) dica et nonnulla alia, post XXX annorum (cap)tivitatem, libertate donata, exibunt. Bene vale et me, qui te sub ferula Ottoniana amabam et adhuc amo, redama. Iterum vale, VulcaNI doctissime, et JaNo DOUSAE, patri itemque filio ingeniis singularibus a me salutem officiosissimam ut dicas rogo. Heidelberga, pridie Cal. Octobris 1591 .

Tuus ad officia,

\section{HENRICUS SMEIIUS, M. D. eiusdemque profess.}

(Adres) Clariss. doctiss.que Viro D. BONavenTURAE VULCANIO Graecarum literarum profes. sori, amico antiquissimo.

Lugduni Batavorum.

II.

S. P. Literae tuae prid. Kal. IIX bris scriptae, XIIX. Xbris mihi redditae multis nominibus gratissimae acciderunt; primum quod iucundissimam illius temporis memoriam quo pueri una sub Otthoniana uti dicis ferula egimus, refricent, tum quod de Cl. viris D. JUNIo et D. Melisso ca quae maxime scire cupiebam significent.

De te non audieram tantum antehac multa mihi iucunda ex aliis. sed et abs te ipso non semel salutem acceperam et honorificam mei mentionem abs te factam in JaNi DOUSAE Encomiis intellexeram; ad quae benevoli erga me animi testimonia, accessit nunc epistula tua eiusdem benevolentiae testis amplissima, cui quidem fuvendae augendaeque equidem non deero; et certe committere non debemus, ut amicitia adeo felicibus auspiciis iacta nostra culpa et vecordia intermoriatur, praccipue cum in tanta sup cor stös ac commilitonum literariorum turba, quantam apud communem utriusque nostrum praeceptorem olim fuisse meministi, adeo pauci sint qui in Musarum castris assidue sese continuerint, aut alioquin ad aliquam frugem literariam pervenerint. Praeter UTENHOVIOS enim puto esse neminem, et de iis magnum iam per multos annos silentium.

Hortor itaque te et rogo, mi SMk'r, ut veterem atque adeo a teneris, quod aiunt, ungui. culis, initam amicitiam, longa iam desuctudine et locorum seiunctione interruptam, instauremus sancteque in postcrum colamus. Postulat hoc et suo quodam iure a nobis exigit patriae, nominis, institutionis, studiorum denique societas et similitudo, planeque nostrum, ut HoRATI ${ }^{2}$ ) verbis utar, consentit astrum. Ne itaque nobis desimus iterum atque iterum rogo. Facile vero vetus atque, ut dixi, propemodum deperdita amicitia redintegrabitur, frequenti inter nos literarum missitatione; quae aliud nobis ex alio cottidie argumentum sint suppeditaturae. Poëmata tua iuvenili aevo abs te condita, avide exspecto, imo et quae iam sunt edita.

1) De catalogus is eerst ruim een eeuw later verschenen (toen de handschriften reeds lang naar Rome weggevoerd waren) o.d.t. Fr. Sylburgi Catalogus codicum Graecorum M.S.S. olim in Bibliotheca Palatina, nunc Vaticaia asservatorum etc. Francofurti ad Moenum Izor, in den bundel die ook met den titel: Monumenta pietatis etc. voorkomt.

2) HoR. Od. II. I7. 22 . 
Nam Iambos tuos, in quibus mei mentio, de quibus mecum egit non semel Dousa noster, nondum mihi, quod doleo, videre contigit. Fieri potest ut et ego aliquando lusus meas iure. niles extrudam ut publicam iudiciorum aleam subeant.

De D. Junio sunt qui nobis spem faciant, utinam ne frustra. Felices nos si tanto viro potiamur. Sed vereor ne Illmus Princeps vester fulcrum illud et columen Academiae suae subtrahi patiatur. Sed et HoRATIl ") illud hodie apud multos locum babet : "Virtuten incolumem odimus, sublatam ex oculis quaerimus invidi." Qua vero in aestimatione apud vestros theologos ille sit, equidem non satis scio. Mibi vel eo nomine est magnus, quod a spincsa illa et contentiosa Theologia alienus esse videatur.

De SCALIGERI adventu param spei. Haeret tamen adhuc in Gallia TuNingius noster ad eun evocandum missus, cum proxenata BAUdio ${ }^{2}$ ).

Catalogum Codicum Mss. qui in Bibliotheca Palatina exstant proximis nundinis proditurum gaudeo. Mirum est nihil hactenus ex ea prodiisse singulare, hoc est veierem aliquem historicum Graecum vel novum, vel emendatiorem et auctiorem. Sed de his plura ad Melssum.

ObsopaEus ${ }^{3}$ ) quid molitur? Ostendit mihi cum hic esset non pauca quae iam habebat affecta: Epigrammata et poëmata veterum poëtarum; et nescio quae alia vel iam propemodum perfecta, vel editioni parata. Saluta eum quaeso meis verbis, ct vale. Lugduni Batavorum, prid Natal. Nomiri 159 I.

Tui studiosissumus

B. Vulcanius.

\section{III.}

Literae tuae, optime VulcaNi, quos pridie natalis Dominici emissas hesterno die accepi, ita me recrearunt, ut nullae multo tempore amplius, eo potissimum nomine quod amicitiam inter pueros ante annos 40 fere inchoatam, et perpetuo interim silentio tantum non emortuam. resuscitare deinceps postliminio ct communi hoc nostro canescente aevo, literularum scriptione refocillare velle mutuo videaris. Ligo sane officio meo non defucro. Licet ante nuperrimam scriptioncm nullas ego ad te, quod meminerim, a pucrili illo tempore literas, interim meas aliquot salutes ad te perlat as gaudeo: tibique constare de publico meae erga te vetcris benevolentiae tcstimonio laetor: quod Douzanis Encomiis anno 1585 lusum inseri sum passus, quamvis antea necdum quicquam meorum evulgaram. Victus tamen pertinaci D. POSTHII efflagitatione id feci. Quia autem intelligo te illud necdum vidisse et exemplar quod mittere possem, nullum esset: idcirco pauculos versus inde decerptos chartulae illevi, donec exemplar nancisci potero. De poëmatiis nostris edendis, quamvis tecum Melissus, Posthius, Gruterus et alii quibus ostendi moneant urgeant, minus tamen nunc hoc tam oculato et delicati oris aevo, festino, quam in adolescentia quum tamen et magnus ille LoTICHIUs ante XXX annos hortaretur, praesertim Reges meos. Multa cnim iam senior considero et deprehendo, quorum si tunc cdita fuissent jam poeniteret. Ad iudicia doctorum et artificum lubenter examino et castigo. Tua, qui ingenio semper felicissimo, ideoque et propter mores carus mihi, iamdudum omnia publicata, licet mihi nondum visa, putavi. Junius noster vir in omni linguarum atque eruditionis genere (pene nisi invidiam metuissem dixissem) summus, eo est loco apud viros literatos et prudentes, quo debet, etiam apud theologos modestiores. Si qui sunt alio ingenio ct iudicio depravato, quid illos moramur? Apud principem et hunc (), et defunctum 5) eorumque consiliaros integriores

1) Hok. Od. III. 24. 3I.

2) Men weet dat Scaliger toch in 1593 naar Leiden kwam.

3) Dit is Johannes Opsopaeus, die na zijn medische studiěn te Parijs voltooid te hebben, een reis door Engeland en Holland maakte, om daarna professor te Heidelberg te worden. Hij overleed 1596.

1) FREDERIK IV.

5) Johan Casimik. 
nullus nec erat nec est pluris. Et licet in regis Galliarum gratiam, abitioni eius in aestatem futurae uterque ante Cal. Janu. con(ces)serint licet inviti et cum conditione: mussitatur tamen rursus a funere senioris, de illo retinendo. In luctu nos esse et quidem gravissimo, ob Jo. CAsinrar fortissimi atque pientissimi heroï obituin, VI Jabu. mane factum, per tot dierum intervallum, ignorare non potestis. Lacrimarum nostrarum testimonia hic vides. Parentalia a Melisso nostro, Posthio aliisque conscripta coactus; fui et a meo dolore elegiam lugubrem adiungere '). Sed quid? SCALIGER vir tantus Leijdam? Utinam possitis. At metuo: hisce turbis et terra et mari Galliae et Bataviae communibus, difficulter dimovebitur. Remittit tibi salutem Opsopaeus, dicitque scripta illa veterum poëtarum exspectare Lutetiae libcratorem regem Galliarum. Salutat te JunIUS, qui in Galliam iturus istuc venturum et se vos visurum promittit; dices officiosam salutem meis verbis Jano DOUzaE patri itemque filio, fama et scriptis, quam facie mihi notioribus. Quia autem VULCANII cognomen fortassis significatione meo affine est (SMET videlicet) cupio scire de parentela tua et insignibus avitis, utrum praeter cognomen et patriam aliud quid commune habeamus nobis ignotum. A scriptione harum exemplum unum Encomiorum tandem ab amico quodam impetravi, quod mitto ut legas. Vale feliciter, et memoriam nostri cum benevolentia mutua conserva. Heidelberga 6 Febru. veteris. anno I 592.

Tui studiosissimus

HENR. SMETIUS.

Levini Ba1ti consobrini mei Med. Profess, et Doctoris in Acad. Rostoch. filius, ante pauculas hebdomadas puta 16 Decemb. hic una cum aliis nonnullis in doctorem utriusque iuris cum laude promotus est, patri suo cognominis.

Scire cupio aetatem tuam, ego an. I537. Junii 29, Alosti me natum credo.

Mitto Parentalium exemplar I domino DOUSAE patri, missurus et filio, sed nimiam sarcinam nuncio metuebam, quamobrem commune utrique erit.

(Adres) Clarissimo doctissimoque Viro

D. Bonaventurae Vulcanio Graecae

linguae Professori, amico veteri.

LUGDUNi Batavorum.

\section{IV.}

S. P. Recte facis, optime SMeti, qui VulCanrum popularem tutum, tibique cognominem, et a teneris, quod aiunt, unguiculis notum, atque adeo in eodem ludo doctum, amore tuo complecti pergas. Facis id, et facies, mihi crede, mutuo. Nam generis splendore fieri potest, ut fuliginosus VULCANIUS tibi cedat; amore $\dot{\alpha}_{i}$ or $\beta$ ati nequaquam nec unquam.

Patcr mihi fuit Petrus de Smet Brugensis; cui Erasmus, quo (ut ex literis ipsius manu

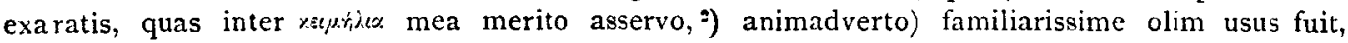
VUrc.ANII cognomen ei indidit. Egit is primum patronum causarum Brugis. Inde Lovanium se recepit, postea in Zelandiam evocatus, syndicum Midelburgensium egit. De stirpe mea parum mihi constat, quippe qui septennis cum patre patria excesserim, neque ab eo tempore in ea domicilium habui, neque ibi unquam ultra biduum sum commoratus. Audio csse nobilem aliquam apud Flandros Smetrorum familiam, e qua si originem ducis, gratulor. Ego hoc tantem scio,

1) Sein Tod hat eine ganse Literabur hervorgerufen. Wir besitzen Leichenreden . . . Klagreden . . . einer Menge kïrzerer Gedichte, Lipiraphien und flicgender Blätter nicht zu gedenken. Häusser, Geschichte der rheinischen Pfals, 1I, p. 172.

MELISsus' bundel neb ik niet kunnen vinden. SMetius' gedicht stat in zijn 7 fuvenilia, ze gedeelte p. 98 .

2) Onder de papieren van Vulcanius wordt nog een brief van ERAsmus aan diens vader bewaard, die van Oct. Pasch. 1533, bij CLericts, p. 1465 , no. 1246. 
parentem meum id ipsum quod CiCERo de se iactare solere quod maioribus suis pracluxisset. Gratum vero erit mihi, si de tua stirpe, et familiae tuae insignibus et quos Brugis affines habeas plenius aliquid ex te intellexero. Natus sum anno $153^{8}$ mense Julio, aetas utriusque nostrum bene consentit, spero etiam astrum.

De obitu Principis ${ }^{1}$ ) vestri sinister rumor aures nostras perculerat; scripseramque ea de re

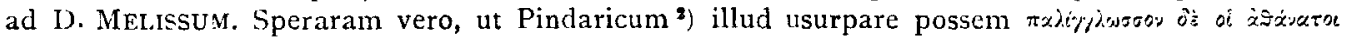
árièn p. video, verus ille rumor. Sed quia hac de re plura ad MeLissum, supersedeo eorun repetitioni. Elogia Dotsana mittis ut legam. Anne etiam ut lecta remitiam? faciam, si volueris. Sin minus, retinebo.

De SCaligero scribo etiam ad D. Melissum. Cochlinus ") de quo adsciscendo in Praesidem Collegii Ordinum Hollandiae agitur ${ }^{3}$ ) commendavit nobis viros aliquot pios et doctos, qui ex Academia illa Saxonica 4), iam, ut aiunt, dissipata, evocari possent. Monebo te, si quid decretum fuerit. Tu me, obsecro, si quid de D. Junso, quem ego intimitus amo, eumque ut officiose ex me salutes rogo. Vale.

Lugd. Batavorum, 18 Martii 1592.

Tui studiosiss.

B. Vlilcanius.

V.

S. P. Gratum admodum mihi aceidit, mi Vulcani, quod de parentela, patria atque aetate tua ad me pcrscripseris, et amicae meae curiositati obsecutus fueris. Sic enim mihi perstaseram nos actate perparum differre, cognomine et patria pene pares. De meis sic habeto: patrem Robertum de SMET, ex Henrico prognatum et Margareta familiae SCorissiae, quae Haronibus clara fuit, adeoque anno I466 Ludovicus ScoRissius Baro supremum civitatis Ganla. vensis praetorem agebat. HENRICUS DE SMET avus patrem habuit JODOCUM supremum civitatis Alostensis praetorem, matrem vero MARIAM SCOUTETTAM, quae toparchiam Ledanam viro in dotem attulit, milliari ab oppido distantem.

Idem JoDocus antca Teneramondani territorii praefecturam administraverat. Cuias autem proavus meus fuerit non constat. Coniicio autem Scuvtetros Brugenses csse, sic enim legisse videor alibi in Mevfri Annatibus \%). Quod si est, putarem ex eadem urbe et proavum oriundum. Quamvis sint et mihi cognomines alii DE SMET, etiam Alosti, sed nulla affinitate iuncti sunt; etiam Gandavi, nibilo magis quod equidem sciam mihi sanguine propinqui. Quin etiam Rostochii nec non hic ad Rhenum eodem cognomine quosdam uti novi. Et quamquam intra 300 aut plures aut pauciores annos ex una familia aut stirpe varie divisa, multi nepotes orti, in alia loca migrare, ibique domicilium eligere et posteros relinquere possint: eaque ratione origo eorum primaria in oblivionem veniat: est tamen una certitudinis via, videlicet insignium exploratio. Nostrae quidem prosapiae sunt tres lunulae tigillo nigro intersectae in clypeo candido. Avus meus HENRicus toparcha Ledensis, Patri Jovoco in praefecturam Alostensem successit, ut a maioribus accepi. Ante consulatum saepius in urbe obiverat quod solorum nobilium munus semper fuit. Sed in bellis Flandricis tempore Maximiliani captus a Gandavensibus, ut se redimeret toparchiam vendere coactus fuit. ROBERTUS SMETIUs eius filius qui mihi pater fuit,

1) Johan Casimir, overl. 6 Jan $\mathbf{5} 592$.

2) PIND. Nem. I. 58.

3) Cuchlinus aanvaardde den post van Regent van het Staten-College in Oct 1592.

4) Wittenberg.

5) Commentarii sive Annales rerum Flandricarum Libri Septemdecim autore Jacobo Meyero Baliolano. Eerste nitgave Antverpiae in aedibus JOANNIS STEkLSII $15^{6} \mathrm{I}$. 
parentis bonis belli et captivitatis calamitate attenuatis, ad literarum et medicinae studia animum applicans, senatorem simul et medicum in patria, dum viveret, egit; obiit sexagenario maior, ante annos quinquaginta. Fratris mei liberi, qui me maior erat, praedia SMETIorcm avita in rure Ledano adhuc possident, domusque in clivo posita ab iniuria seditionum nostrae temporis intacta et incolumis per Dei gratiam, ut intellego, hactenus permansit. Supra proavum nullius mihi est memoria, parentem enim nondum iuvenis amisi.

Exemplar illud Elogii Dusani quod attinet, non misi ut remittas, neque est milhi co opus quum aliud mihi supersit; ut nihil aliud, saltem vel illud mei apud te memoria maneat.

Quod de viris aliquot piis et eruditis ex Saxonicae Academiae dissipatione ingruente evocandis cogitatis, pic sane vobisque utiliter facitis. Cogitant et nostri de quibusdam, inter alios de D. Calamino: facta est et D. Wesenbecil et D. Eberhardi Weinil mentio ${ }^{1}$ ). Quid autem futurum ignoro. De Jusio nostro scito eum valere per Dei gratiam et vos ex itinere visurum, adeoque fortassis aliquantisper apud amicos haesurum: sic enim omnino statuit volente Domino, et tibi salutem renunciari petivit vicissim. Vale Heidelberg, 22 Aprilis 92.

Tui studiosiss.

SMETIUS.

(Aưres) Clarissimo et doctrinae praestantis

viro D. Bonaventurae Vllcanio Graecae

linguae professori, amico antiquo.

LUgDUNi Batav.

VI.

Salutem a te mihi annunciavit nuperrime gener meus suavissimus Gruterus, Vulcani clariss. et amicorum meorum qui vivunt, ut opinor, antiquissime, quae sane mihi gratissima fuit. Qu um autem scire avens, quo in literario ludo olim una vixerimus, dicam: Non Brugis, nec Diesthemii, non Mechliniae nec Lovanii, verum Gandavi, JoAnNem OTTHONEM praeceptorem communem habuimus, cui Matthaeus Richius et Joannes Olearius hypodidascali operam navabant, ab anno 1552 usque ad 1554 quo Lovanium in aestate me contuli. Vidi illic FruTerium, Nicolaum, Carolum, Jacobum, Aistonium, Jonnnem Utenhovios fratres, Vhchtanium, Cuemiterium, dammannum, Franciscum et Carolum Kethullos fratres, Harduwinum, Juannem et Lucam Maiardos fratres, Petrum Preisium, N. Gualterum, Paul. Knibibium, Hauldionium 2), Levinum battum, Wilhel. Lapidanum, Corn. Taimondum, Tayardum, Exardum, Levinum SANDriUm, EMbisium et duos Verhagios fratres Michaelem et Jacobum Antverpianos, nec non Henr. Corputium. Reliqui iam non succurrunt. Tu in prima classe cum Utenhovis maioribus versabaris, statura breviuscula, anno aetatis ri fallor XVI, ingenio eleganti, in versibus scribendis socios superans, quo studiorum genere et ego delectabar, pari tecum aetate, sed classe et eruditione te inferior, natus puta 29 Junii 1537, Alosti. Vertebam autem anno 1553 PצriraGORAE aurea carmina, nec non PHUCYIIDAE gnomas versibus Latinis. Postea Batrachomyomachiam Homeri an. 1555 Lovanii; Susalnam et Reges Iudaicos lib. tribus, partim Lovanii, partim Rostochii, partim Heidelbergae an. 1559 ubi PeTru LotTichio illos ostendi qui de publicandis monebat. Deinde an. 1560 in Italiam profectus, sequenti Januario gradum doctoratus in Medicina una cum Levino Sandrio Bononiae adeptus sum. Anno vero i $562 \mathrm{~m}$. Janu. uxorem duxi et medicam artem exercere coepi Antwerpiac. An. 1567 Comitibus Lippiensibus et reipublicae

1) Van deze drie is alleen Calaminus naar Heidetberg beroepen. Hij overleed daar 25 Nov. 1598.

2) Een onduirelijke correctie maakte dat Vulcanius "Charidonius" las. Bedoeld is: de Haudion. 
Lemgovianae stipendio per annos sex obligatus vixi. Inde Maio mense 1573 fleidelbergae in aula Electori FrIderico III per quinquennium medicum egi. Ab anno 1578 (quo te Francodaliae una cum Barone S. ALdegundio ${ }^{1}$ ) in prandio Bembergano vidi) usque ad annum 1585 principi JoAn. Casimiro (artem docendo, et faciendo, tum in schola, tum in aula) inservivi. Ab eo terrpore huc ab Academia vocatus, in statione Med. docendi per annos XXVI persevero. Poëmata mea, hortatu Mecissi, in lucem eduxi an 1594. Prosodiam meam sexies, ut audio, impressam, brevi, uti spem tacit Jonas RHodius septimo excudet cum auctario aliquo. Vernis nundinis prodibunt, volente Christo domino, Miscellanea nostra medica, anno aetatis meae quarto supra LXX. Habes hic breviter decursum vitae SMetranae. Quod reliquum est precor Dominuin Jesum Dei filium ut utrique nostrum in agnitione et timore sui cum firma fide et spe vitae caelestis, terrenam hanc et calamitosam (in qua quidem iam mediocriter pro aetate per Dei gratiam habeo) finire concedat. Foeliciter vale, Vir clariss. Kal. Decemb. I6Io. Heidelb.

Tui studiosiss.

HEN. SMETIUS.

Mitto tibi vultum meum cum atavitis insignibus.

(Adres) Clariss. doctissimoque viro Domino Bonaventurae Vulcanio, professori Graecae linguae, amico antiquissimo.

Leidae.

VII.

Gratissimae mihi acciderunt Vir Clar.me literae tuae, quod veteris nostri apud OTrHONEM contubernii memoriam refricarent et SMETIANAE vitae decursum recenserent. Excideras profecto animo meo, mi SMETI; quod inde factum arbitror, quod neque unius scholae, neque unius classis essemus, eamque ob causam minus familiariter alter altero uteremur. Agebat tum temporis etiam apud OtThonem quidam Petrus Vulcanius, claudus si bene memini, sed nulla affinitate mihi coniunctus.

Reliquorum condiscipulorum, quorum mentionem facis, memoria adhuc animo meo inhaetet, praeterqaam P. F'REISI, N. ChARIDIONII, VRRHAgIORUM fratrum et CorPuII. Ex aliis velim scire an aliquis etiamnum sit superstes, et ubi locorum degat. E scriptis tuis nihil quod sciam vidi praetcr Poemata anno 1594 edita. Miscellanea medica, si vernis hisce nundinis prodibunt in lucem, fac quaeso ut ea videam. Effigies tua mirifice mibi placuit, ut et epigramma cl. v. JANI GRUTERI generi tui, in quo optime expressa est pietas et modestia tua singularis, quam muta

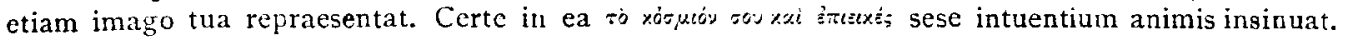
Ex ea video te anno uno et die uno me esse maiorem. Natus enim sum An. I538 Junii die trigesimo.

Deus te quam diutissime prospera valetudine truentem conservet. Ego iam quadriennium totum cum gravissimis morbis conflictor, quorum longa enumeratione quid attinet tibi fastidium creare. Summa haec est: visum, auditum, manus, pedes ac latera omnia esse valde imbecilla, ut ad omnes corporis functiones sim fere $\alpha \chi_{0} \operatorname{rros}_{5}$ et per XIV menses pedes cubiculo aut certe domo non extulerim, adeo ut mirum non sit rumores passim sparsos me pluribus additum.

Bene vale vir Clarme. et me amicissimis literis tuis interdum, quod commodo tuo fiat, recrea. Erit id mihi longe quam gratissimum.

1) Vulcanius vergezelde Marnix als secretaris naar den Rijksdag te Worms. Een brief van MarniX van I8 $\mathrm{Mei}$ is te Frankenthal geschreven. Oeuvres ed. Lacroix, Corresp. p. 244. 
Cl. V. domino Jano Grutero genero tuo multam quaeso ex me salutem dicito; cui nunc temporis non scribo quod quae de me scire cupiet commodius pleniusque e Bonaventura ZISENDRIO cognoscet. Significa etiam quaeso me vehementer exspectare num ad literas meas quas ei superioribus nundinis ad H. PETRI HERDESIANUM curandas miseram, responsi aliquid allatum sit.

Receperat (uti ad me scripserat GrUTERUS) id negotii in se Clar. D. Freherus, ex quo velim resciscat, quid literis meis, quas ad HERDESIANum scripseram factum sit simulque roget, ut ad literas etiam meas respondere dignetur. Iterum vale.

Lugd. Batavorum i8 Martii I6II.

'Tui studiosiss.

B. VULCANIUS.

(Adres) Amplissimo Nobilissimoque Viro, Dno.

Henrico Smetro Illmi Principis Electoris

Palatini Medico etc. amico antiquissimo.

Heidelbergam.

VIII.

Literas tuas amicorum antiquissime 18 Martii ad me missas accepi, quae mihi acciderunt onge gratissimae, eo quod tum a te venirent, tum rerum tuarum statum praesentem declararent: qui licet subtristis esset, propter senectutis incommoda, variarumque corporis partium

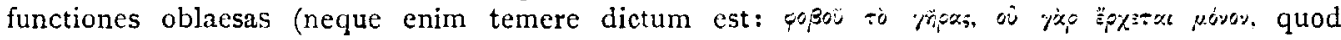
Elegiarum mearum lib. 1, elegia $2^{1}$ ) adolescentulus explanabam) placuit tamen hoc quod visitationem Domini te patienter ferre videam. Delectionem enim Dei inde colligere licet, sicut docet Salomon Prov. 3 v. II: "Eruditionem Jehovae fili $\mathrm{mi}$, ne spernito, neque taedeat te correctionis eius. Nam quem diligit Jehova, corrigit, et quidem ut pater filium, cui bene vult": Imo Jobus 5 v. 17 inquit: "Ecce beatus est mortalis, quem arguit Deus, quapropter castigationem omnipotentis ne spernas." His consentit epist. ad Hebraeos 12 v. 6. Imo ipse Dominus Apoc. 3 vo Ig ait : "Ego quos amo, arguo et castigo. Aemulare igitur (inquit ecclesiae) ac resipisce." Sunt enim transgressiones nostrae et delicta iuventutis, quae virgam Domini provocarunt.

Ad veteres condiscipulos nostros quod attinet, qui sub ferula Otthoniana quondam nobiscum studuerunt, neminem putem superesse: praeter Michaelem Verhagium, dominum de Mafra, mihi aequaevum Antverpiae, qui ut adolescens solebat, ita adhuc in Parnasso versari non desinit. Vivit quoque etiamnum Jacobus Verhagius, eiusdem frater minor, sed Mercurio magis quam Musis aut Minervae deditus.

Restat praeter hos CaRolls BatTuS, LevinI frater, medicinae licentiatus, vir sentuagenario maior, artem Amstelodami factitans. Dubito an LUCAS MAIARDUs inter Embdanos adhuc, simul et TAYARDUS vitam agant. Nullos praeterea novi.

Prosodia mca, quae Syllabarum dipbthongas et positione carcntium quantitatcs, sola veterum Poëtarum authoritate, adductis exemplis demonstrat iam septimo chartis 44 excusa et quidem cum mantissa prioribus editionibus auctior, prostat apud JONAM RHODIUM Francofurti, excmplaribus supra duo millia rursus impressis, quorum ante ab anno 1599 ad octava millia distracta fuerunt, scholasque totius Europae Latinas adiverunt.

Miscellanea medica, typographo aliis laboribus pluribus occupato, vernarum nundinarum spem quidem frustrarunt, prodierunt tamen his autumnalibus in publicum, chartis quinquaginta forma octava, charactere minutiore quam optassem. Horum exemplar unum ad te mittendum, chartopratae Leidensi ut tradatur, mandavi : varietate rerum utilium lectorem, rei medicae imprimis studiosum delinitum iri spero.

1) Fuvenilia, 2e ged. p. 45.

Oud-Holland, Igo8. 
De valetudine cum mea, tum meorum, non est (singulari Christi Jesu benignitate) quod conquerar, si ingravescentem aetatem excipias; manus enim minus firmae ad scribendum, pedesque minus robusti ad procul ambulandum. Oculi auresque mediocriter officium faciunt. Memoria tamen labascit. Praelegi nihilominus per aestatem auditoribus.

Ad HERDESIANUM quod spectat respondet GrUTERUS, sibi a F'REHERo de responso HERDESIANI ad literas tuas nihil indicatum.

His vale vir clariss. Heidelb. I4 Septemb. I6II.

(Adres) Clariss. doctissimoque viro, domino BONAVENTURAE VULCANIO amico veterrimo.
Tui studiosiss.

H Smetius. Leidae.

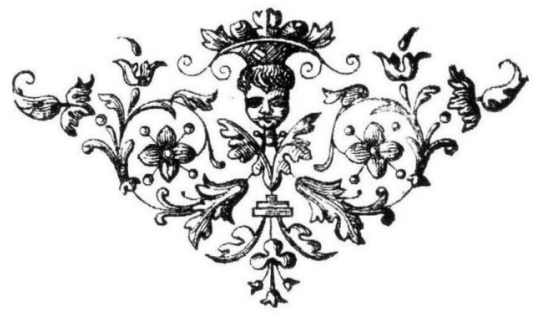

